\title{
Transforming Research Landscape in Africa using Open Access: The case of Ethiopia
}

UCT-SPARC Africa

Open Access Symposium 2019

Cape Town, South Africa

Solomon Mekonnen(PhD)

National Open Access Coordinator

Addis Ababa University

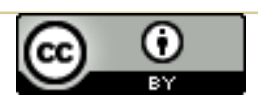




\section{Outline}

- Africa knowledge production

- True marginalization stories

- Ethiopia's approach to avoid marginalization

- National Open Access Policy

- Challenges and Lessons learned

\section{(2) $\frac{(0)}{\mathrm{in}}$}




\section{Knowledge Production in Africa}

"With a contribution of less than $1 \%$ of the world's scientific publications, Sub-Saharan Africa belongs to the periphery."

(Piron et al.,2019)

Source

Piron, F., Nkoudou, T. H. M., Madiba, M. S. D., Alladatin, J., Achaffert, H. R., \& Pierre, A. Toward African and Haitian Universities in Service to Sustainable Local Development: The Contribution of Fair Open Science. CONTEXTUALIZING OPENNESS, 311.

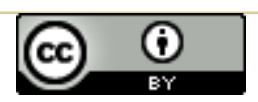




\section{True story of marginalization}

- A story of a medical researcher from Makerere University whose article was rejected because of his affiliation.

- Other cases of rejection

$>$ Local problem

$>$ Language

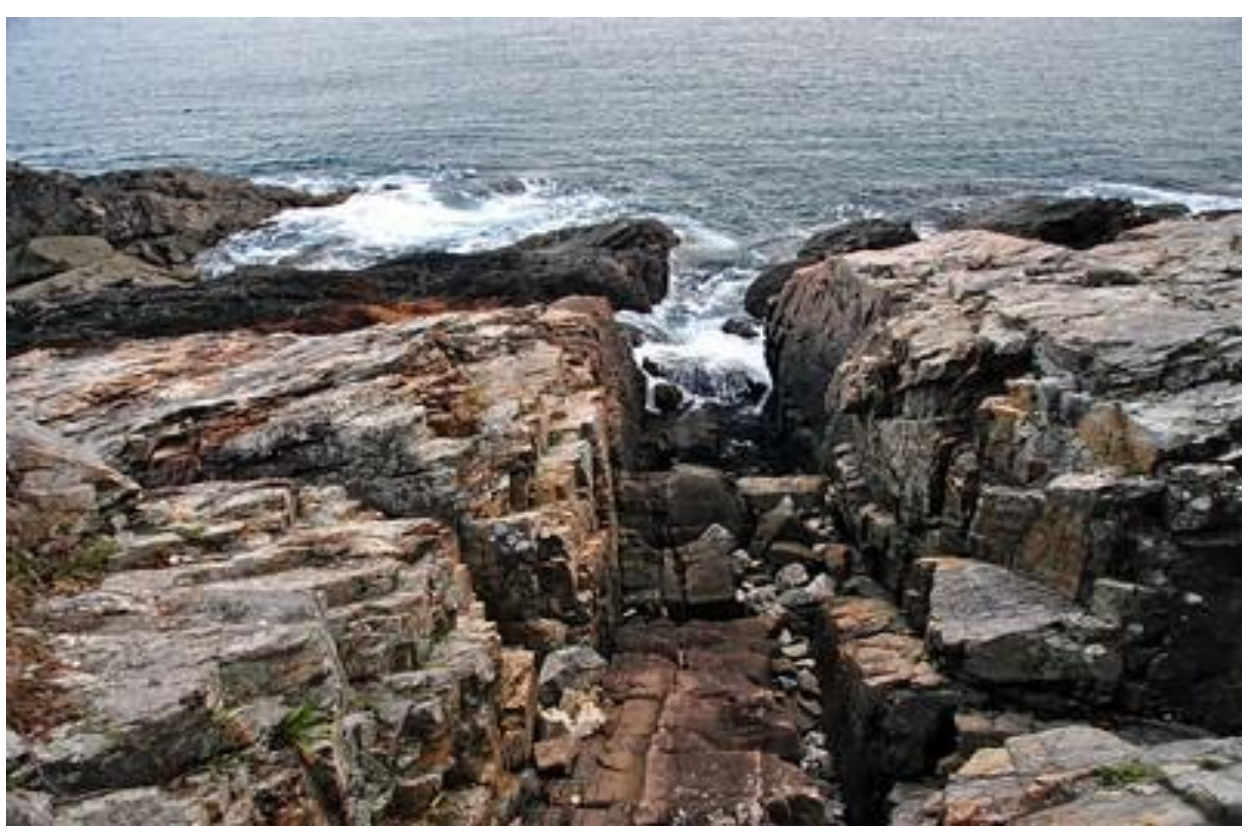

Photo credit to Angel n., CC BY 2.0

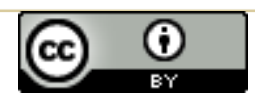




\section{Ethiopia's Approach to avoid marginalization}

- Build local publishing platforms to mainstream our research.

$>$ Repositories

$>$ Journal publishing platforms

- Capacity building for Repository managers, Journal editors and Researchers.

- Making open access the default for research publication using policy.

- Learn from others but contextualize.

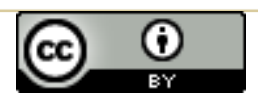




\section{National OA policy}

- Intuitional OA Policy discussion started in Ethiopia In 2014 at Addis Ababa University with support of EIFL.

- National OA policy proposed by CEARL(Consortium of ETH Academic and Research Libraries) in 2017.

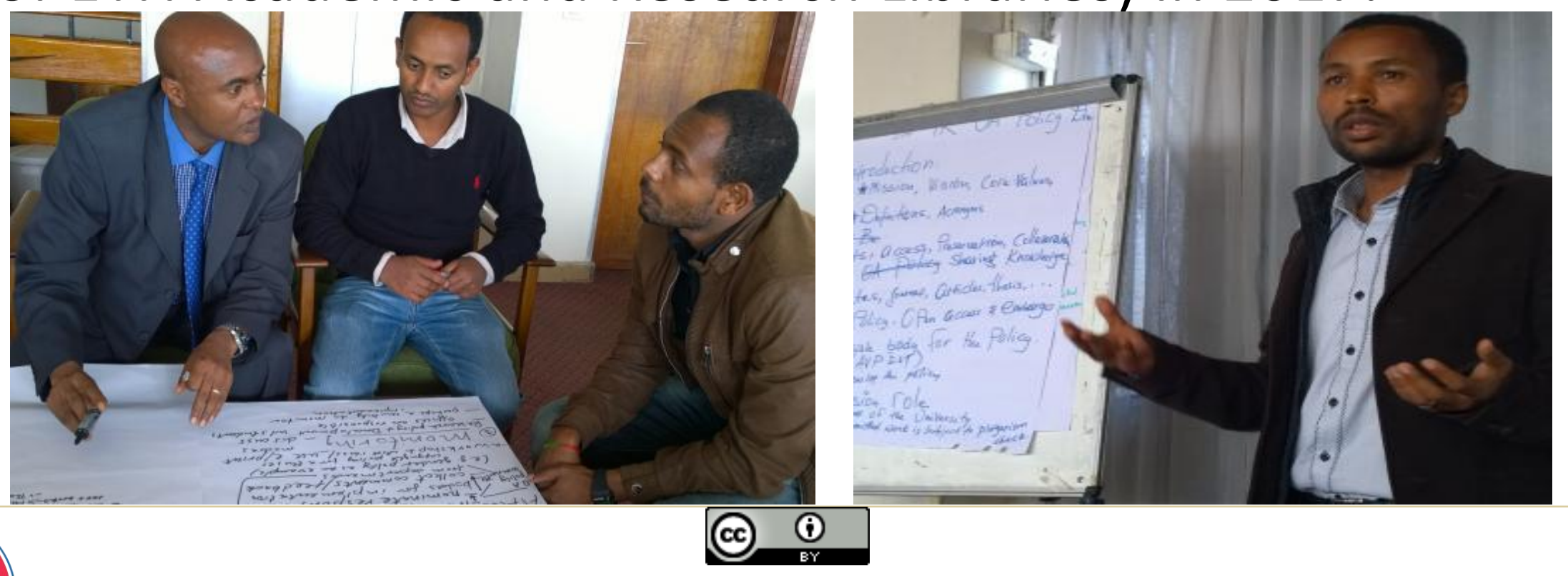




\section{Adopted Intuitional OA policy}

- Jimma University (2018)

- Adama University(2018)

- Arbaminch University(2018)

- Hawassa University (2019)
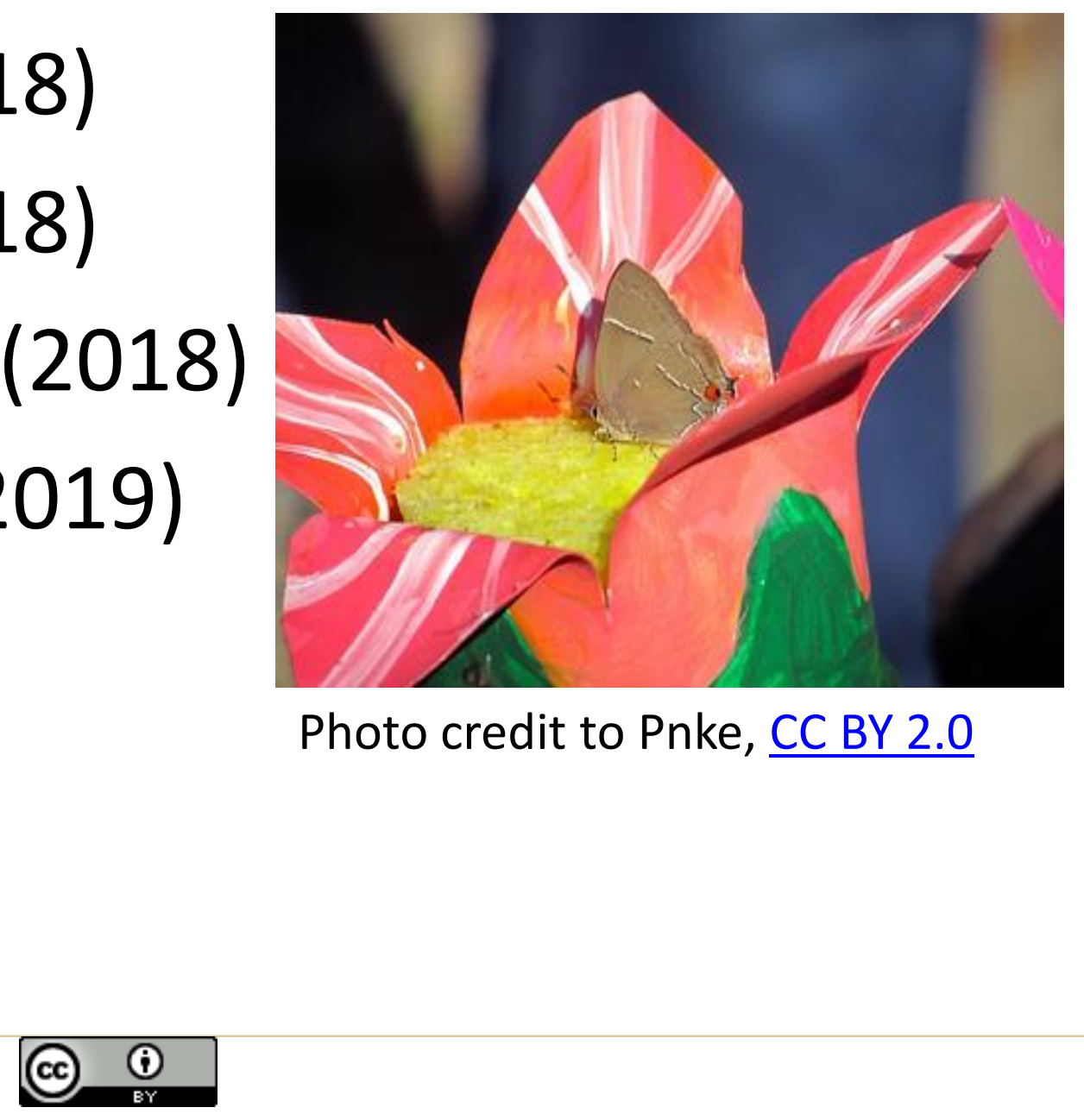


\section{Contextualized National Open}

\section{Access Policy}

- Officially adopted by Ministry of Science and Higher Education (MOSHE) in June 2019.

- Holistic approach addressing all areas policies, repositories, journals, researchers skills.

- Managed by local experts.

- funded by local money.

\section{(c) $\underset{\mathrm{ir}}{\mathrm{in}}$}




\section{Key Requirements of the policy}

- Open Access by Default for all public funded research outputs

$>$ Thesis and Dissertations

$>$ Journal articles

$>$ Research Data

$>$ Journals

- Researchers receiving public funding are required to prepare Data Management Plan (DMP) with FAIR principles.

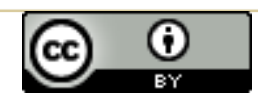




\section{Incentive}

Encourage "Openness" as one of criteria during research during research assessment and evaluation.

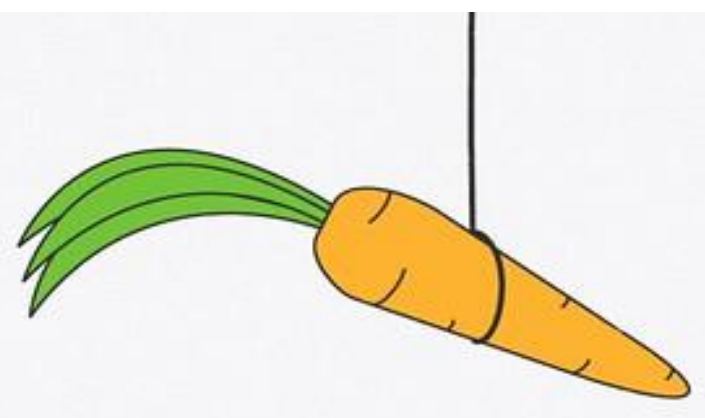

Photo credit to SumAll, CC BY 2.0

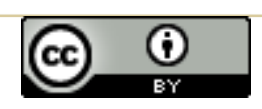




\section{Infrastructure}

- Universities are required to implement and support Intuitional repositories.

- MOSHE supports national repository as aggregator for research publication and research data.
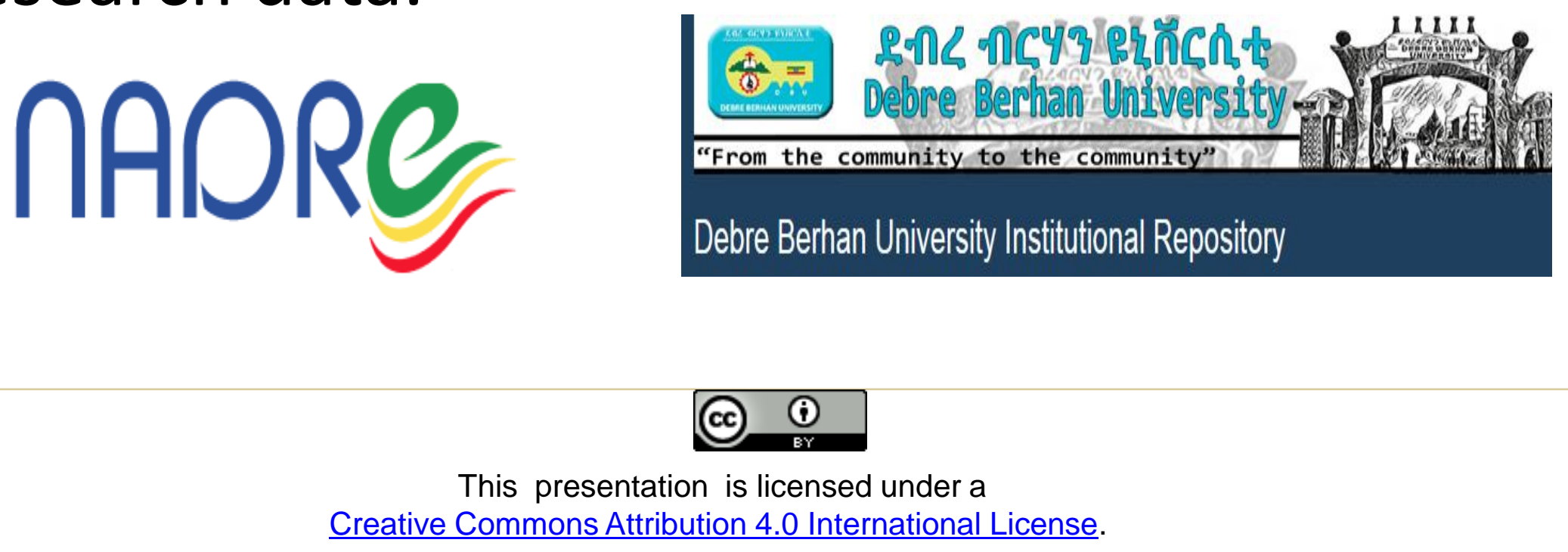


\section{Support for researchers}

- Universities have to ensure open science services and training for their researchers.

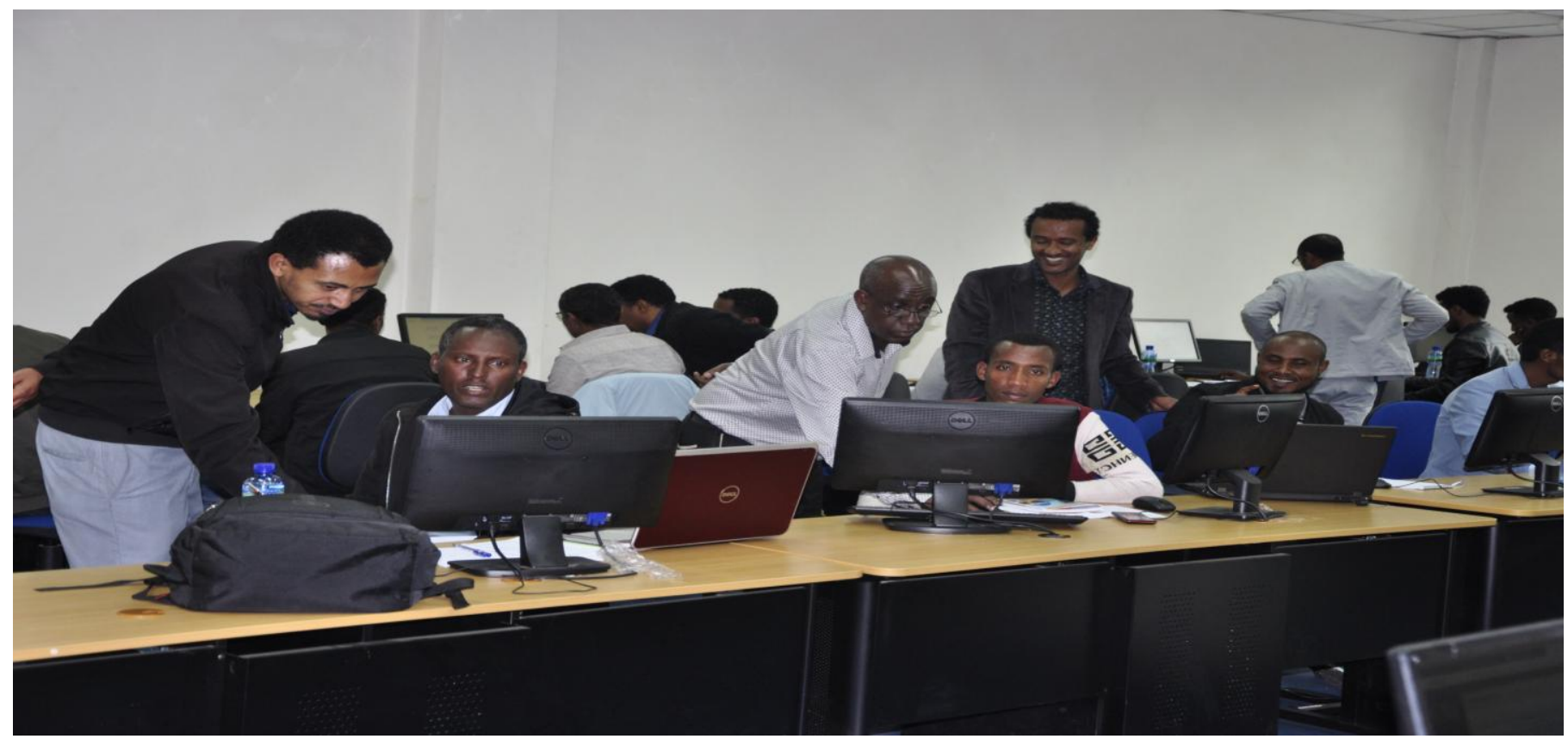

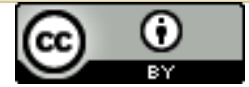

This presentation is licensed under a Creative Commons Attribution 4.0 International License. 


\section{Policy implementation}

- Model IR policy based on National Policy have been prepared and circulated to Universities for adoption.

- A national project on national repository and Journals launched in August 2019.

\section{(c) (1)}




\section{The National OA Project}

- Implement Institutional repositories for all public Universities.

- Capacity building training for repository managers and Journal Editors.

- Supporting the National Academic digital repository of Ethiopia (NADRE).

- Strengthening the Ethiopian Journals Online (EJOL)platform.

\section{(c) (1)}




\section{National Academic Digital}

\section{Repository of Ethiopia (NADRE)}

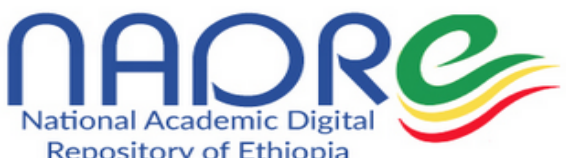

Repository of Ethiopia \begin{tabular}{|l|l|l|l|}
\hline Search & $\mathbf{Q}$ & Upload Cog in
\end{tabular}

https://nadre.ethernet.edu.et/

\section{Latest entries}

\section{December 2, 2019 (V1) Thesis Open Access}

DIMENSIONING OF WIRELESS - OPTICAL HYBRID $5 G$ NETWORKS

HENOK MEZEMR

In recent years, the evolution of mobile networks into $5 \mathrm{G}$ has been developed collectively by the operators, vendors, corporate research laboratories, universities, and the public sector players. $5 \mathrm{G}$ will cover almost all aspects of the human civilization. Employing wireless - optical hybrid.

Uploaded on December 2, 2019

\section{December 2, 2019 (v1) Thesis Open Access}

CAPACITY ANALYSIS OF 5G DENSE NETWORKS WITH MILLIMETER-WAVE SYSTEMS ADDIS GOSHE MIRETU

The fifth generation (5G) network needs to evolve in order to increase the capacity 1000 times higher than the fourth generation of networks by 2025. Small cells (Dense Nets), millimeter wave (mmW) and massive multiple-input multiple output(MIMO) deployment have emerged as key technologies for...

Uploaded on December 2, 2019

\section{December 2, 2019 (VI) Thesis Open Access}

EFFECT OF FINENESS OF SUGARCANE BAGASSE ASH ON MECHANICAL PROPERTY OF CONCRETE

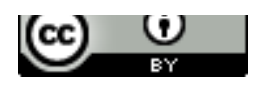

National Academic Digital Repository of Ethiopia

- Research. Shared. - all research outputs from across all domains of Ethiopian research are welcome!

- Findable. Citeable. Discoverable - each upload gets a Digital Object Identifier (DOI) to make it easily and uniquely citeable. You can (automatically) link your research outputs to your ORCID profile.

- Communities - create and curate your own community for a workshop, project, Division. Laboratory, service, journal, etc. into which you can accept or reject uploads.

- Funding - you can associate an upload to the grant that has funded the work.

- Flexible licensing - you can choose among several licenses. You can also upload closed or embargoed research outputs.

Tweets by@PMEthiopia

This presentation is licensed under a Creative Commons Attribution 4.0 International License. 


\section{NADRE}

- Open Access National Repository of Ethiopia for Universities.

- Supports contents for thesis and dissertations, articles, research data and presentations.

- Hosts contents directly and also harvests from existing repositories.

\section{(c) (1)}




\section{Ethiopian Journals Online (EJOL)}

TETHIOPIAN JOURNALS ONLINE

EJOI

http://ejol.aau.edu.et (current site)

http://ejol.ethernet.edu.et (New site)

Search all EJOL Journe Search

JOURNALS

The Ethiopian Journal of Higher Education

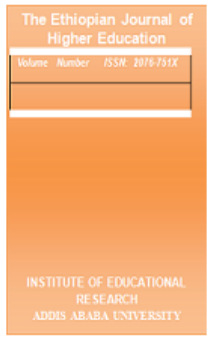

The Ethiopian Journal of Higher Education (EJHE) is one of the publications of the Institute Of Educational Research, Addis Ababa University. The Journal is primarily devoted to disseminating findings of scientific investigations related to higher education. We solicit articles from researchers of high professional caliber. We also accept Commentaries, book reviews and case studies on issues related to higher education. Manuscripts should not exceed 30 pages typewritten on one side of the paper only; and Double-spaced. Commentaries, book reviews case studies and the like should not exceed 15 pages.

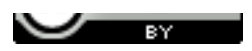

This presentation is licensed under a Creative Commons Attribution 4.0 International License. 


\section{EJOL}

- A platform to publish local open access Journals online.

- An Initiative of Addis Ababa University and EIFL which was launched in 2014 with six Journals.

- EJOL moved to MOSHE in November 2019.

- Currently there are 25 Journals participating in EJOL.

\section{(c) 9}




\section{Building Intuitional Repository}

- An IR platform is implemented at MOSHE data center(Ethernet) to be used by all Universities.

- Customization works for all the Universities in under process.

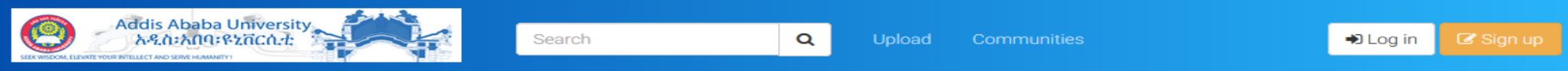

\section{Recent uploads}

\section{July 2, 2019 Thesis Open Access}

Numerical Methods for Solving System of Hyperbolic Uncoupled Pdes

AAU Repository

Anteneh Kiyak

This thesis concentrates on numerical methods for solving hyperbolic un- coupled PDEs systems with two independent

variables (space and time)and whose model problem is $v t+A v x=0$ for which $A$ is assumed to be a diagonalized

matrix;discusses the consistency,stability and convergence based on the

\section{is a digital service that collects.}

preserves, and distributes digital material.

More information.

\section{November 1, 2018 Thesis Open Access}

Charge Transport Across Metal N-Type Semiconductor Interfaces Feredelign Tamrat

In this study, we considered the thermionic emission, field emission and tunneling and we derived current density as a functions of different parameters such as, temperature, barrier height, work function, bias voltage and dopant concentration for thermionic emission, field emission and

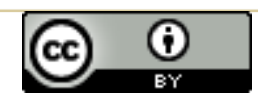

AAU REPOSITORY

- Research. Shared. - all research outputs of

the university from across all fields of

arch are welcome!

- Discoverable. - uploads are visible,

searchable and shareble by everyone.

Communities - create and curate your own community for a workshop, project,

department, journal, into which you can

digital repository?

te an upload to

the grant that has funded the work.

- Flexible licensing - you can choose among

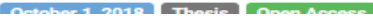

This presentation is licensed under a Creative Commons Attribution 4.0 International License. 


\section{Capacity Building}

- A training on Repository Management has been conducted for all participant from public universities in September 2019.

- A training on Online Journals Management has been conducted for Journal Editors in October 2019.

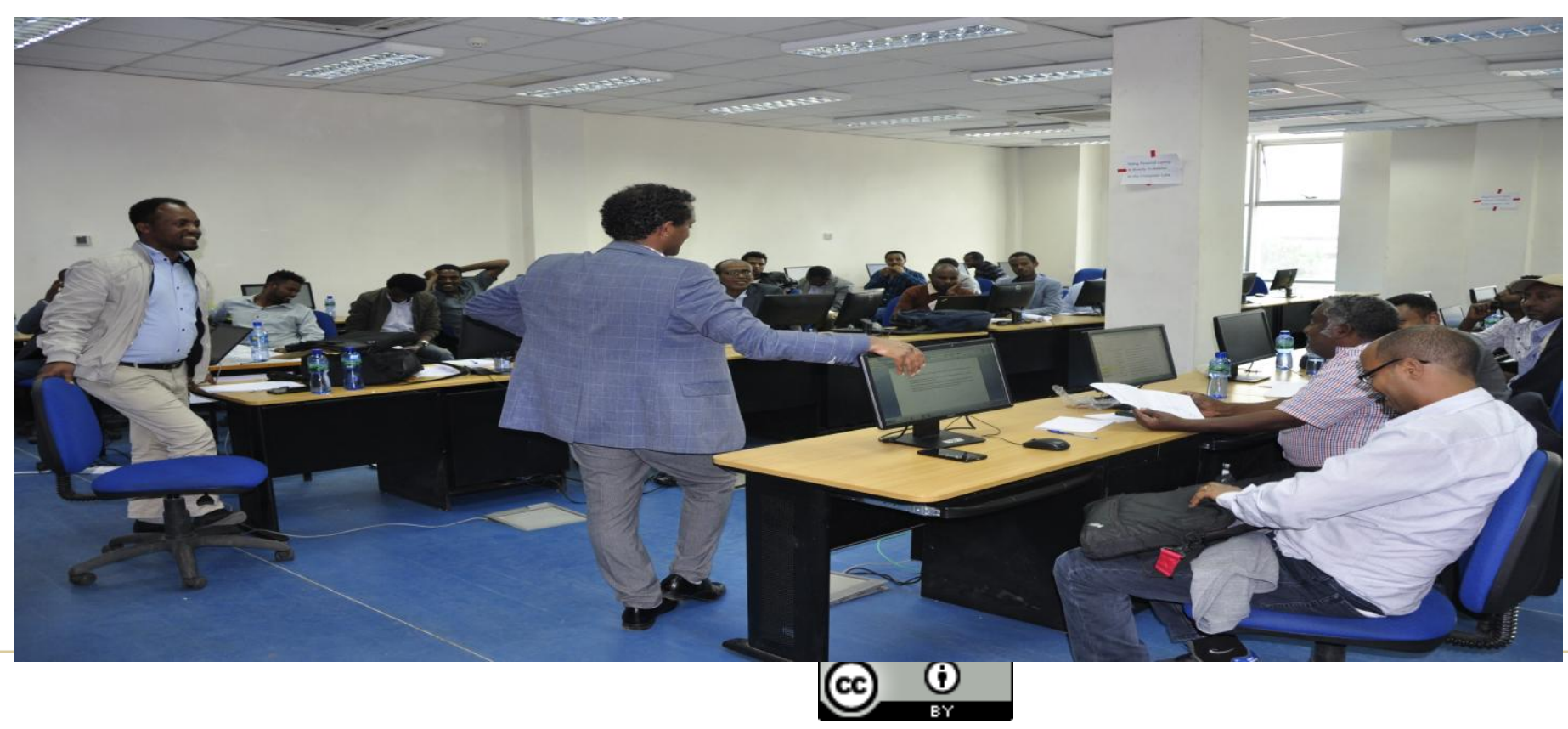

This presentation is licensed under a Creative Commons Attribution 4.0 International License. 


\section{Challenges}

- Long decision making process.

- Dispersed OA initiatives.

- Awareness and skill.

- Managerial turnover.

- Restructuring of Universities and Government Ministries .

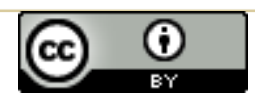




\section{Lessons learned}

- Advocate for both IR policy and National policy in parallel.

- Consolidate OA Advocacy

$>$ Library Consortia, National research and education networks, Ministry of Education, Policy and strategy centre, and Academy of Science .

- Create OA champions among researchers and policy makers.

- Use OA show cases to support advocacy

- Contextualize and locally own the process. 


\section{International Partners}
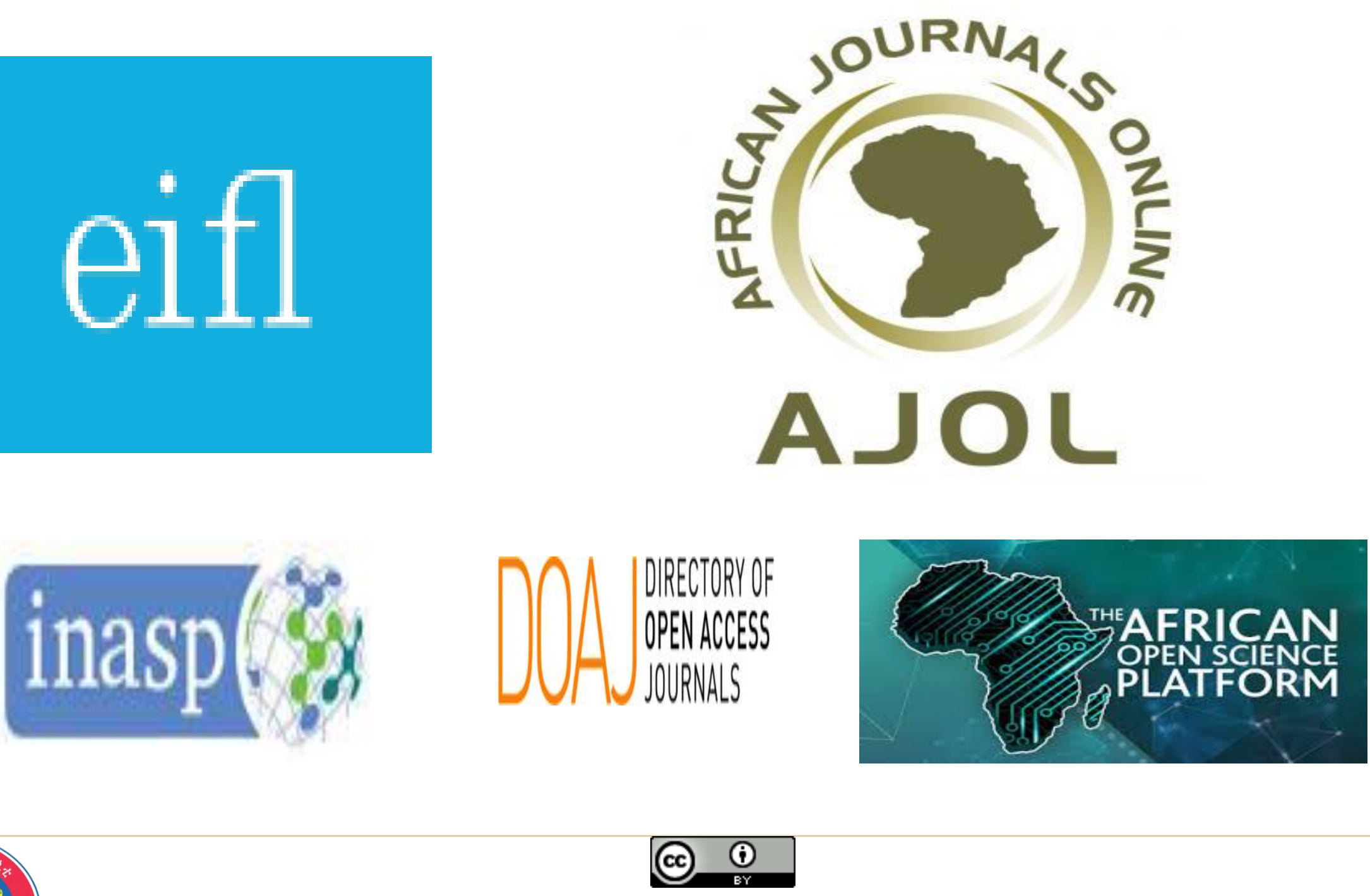

This presentation is licensed under a Creative Commons Attribution 4.0 International License. 


\section{THANK YOU!}

\section{QUESTIONS?}

\section{Solomon.mekonnen@aau.edu.et}

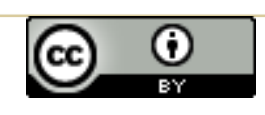

